\title{
Corrigendum: Temporality of Features in Near-Death Experience Narratives
}

\author{
Charlotte Martial ${ }^{1 *}$, Héléna Cassol ${ }^{1}$, Georgios Antonopoulos ${ }^{1}$, Thomas Charlier ${ }^{2}$, \\ Julien Heros ${ }^{1}$, Anne-Françoise Donneau ${ }^{2}$, Vanessa Charland-Verville ${ }^{1 \dagger}$ and \\ Steven Laureys ${ }^{1 \dagger}$ \\ ${ }^{1}$ Coma Science Group, GIGA-Consciousness and Neurology Department, University of Liège and University Hospital of \\ Liège, Liège, Belgium, ${ }^{2}$ Biostatistics, Public Health Department, University of Liège and University Hospital of Liège, Liège, \\ Belgium
}

Keywords: near-death experience, narrative, temporality, feature, sequence, text analysis

\section{OPEN ACCESS}

Edited and reviewed by: Felix Scholkmann,

University Hospital Zurich, Switzerland

*Correspondence:

Charlotte Martial

cmartia/@ulg.ac.be

${ }^{\dagger}$ These authors have contributed equally to this work.

Received: 08 August 2017 Accepted: 15 August 2017 Published: 22 August 2017

Citation:

Martial C, Cassol H, Antonopoulos G, Charlier T, Heros J, Donneau A-F, Charland-Verville $V$ and Laureys $S$ (2017) Corrigendum: Temporality of Features in Near-Death Experience

Narratives.

Front. Hum. Neurosci. 11:435. doi: 10.3389/fnhum.2017.00435

\section{A corrigendum on}

Temporality of Features in Near-Death Experience Narratives

by Martial, C., Cassol, H., Antonopoulos, G., Charlier, T., Heros, J., Donneau, A.-F., et al. (2017). Front. Hum. Neurosci. 11:311. doi: 10.3389/fnhum.2017.00311

In the original article, the name of one of the editors was incorrectly spelled in the reference for "Greyson B. (2000). "Near-death experiences," in Varieties of Anomalous Experience: Examining the Scientific Evidence, eds E. Cardefia, S. J. Lynn, and S. Krippner (Washington, DC: American Psychological Association)." as "Cardefia". It should be "Cardeña." The authors apologize for this error and state that this does not change the scientific conclusions of the article in any way.

\section{REFERENCES}

Greyson, B. (2000). "Near-death experiences," in Varieties of Anomalous Experience: Examining the Scientific Evidence, eds E. Cardeña, S. J. Lynn, and S. Krippner (Washington, DC: American Psychological Association), 315-352.

Conflict of Interest Statement: The authors declare that the research was conducted in the absence of any commercial or financial relationships that could be construed as a potential conflict of interest.

Copyright (๑) 2017 Martial, Cassol, Antonopoulos, Charlier, Heros, Donneau, Charland-Verville and Laureys. This is an openaccess article distributed under the terms of the Creative Commons Attribution License (CC BY). The use, distribution or reproduction in other forums is permitted, provided the original author(s) or licensor are credited and that the original publication in this journal is cited, in accordance with accepted academic practice. No use, distribution or reproduction is permitted which does not comply with these terms. 